\title{
DEVELOPMENT OF A NEW FATIGUE AND CREEP RESISTANT PM NICKEL-BASE SUPERALLOY FOR DISK APPLICATIONS
}

\author{
J.-Y. Guédou ${ }^{1}$, I. Augustins-Lecallier ${ }^{2}$, L. Nazé2, P. Caron ${ }^{3}$, D. Locq ${ }^{3}$ \\ ${ }^{1}$ Snecma, Centre de Villaroche, F-77550 Moissy-Cramayel, France \\ ${ }^{2}$ École des Mines de Paris, Centre des Matériaux, BP 87, F-91003 Évry Cedex, France \\ ${ }^{3}$ Office National d'Études et de Recherches Aérospatiales (ONERA), BP 72, F-92322 Châtillon Cedex, France
}

Keywords: Disk Superalloy, Powder Metallurgy, Microstructure, Mechanical Properties

Abstract

Recent analysis of requirements and limitations in both economics and environmental issues of the development of modern turbine engines has led to redefine the specifications to be filled by superalloys for disk applications. Various criteria derived from these specifications helped to formulate a number of original alloy chemistries. These alloys were produced using powder metallurgy route at laboratory scale for microstructural and mechanical data collection. Two alloys were then selected for production by industrial processes and patented as SMO43 and SMO48. After thermomechanical treatments, the microstructural features and the mechanical properties of these two alloys were thoroughly evaluated. Tensile strength, LCF and FCG behaviours prove to be at least as good as N18's and creep strengths significantly higher. Finally, SMO43 appears to better fulfil the selection criteria.

\section{Introduction}

In modern gas turbine engines, the achievement of decrease in $\mathrm{NO}_{\mathrm{x}}$ and $\mathrm{CO}_{2}$ emissions and noise reduction are stringent objectives in the short term. Increasing levels of fuel economy are also required for optimised acquisition and life cycle costs. These challenges are bound to be taken up through higher overall pressure ratios, compressor discharge and turbine entry temperatures. Consequently, disks in high pressure compressors and turbines will have to sustain higher temperatures and loadings for long durations. So a strong demand appears for highperformance nickel-base superalloys capable of longer service lives in quite severe conditions as compared to the reference alloy N18, which, up to now, is implemented by Snecma in those critical parts.

A cooperative program has been launched between Snecma, ONERA and Centre des Matériaux to develop a new powder metallurgy (PM) superalloy grade with basic specifications as following:

- capability of significant grain size evolutions through thermomechanical treatments and, particularly, ability to supersolvus solutioning which implies limited contents of $\gamma$ ' phase,

- metallurgical stability for long time exposures up to $750^{\circ} \mathrm{C}$,

- higher creep and fatigue resistance as compared to N18 up to $700^{\circ} \mathrm{C}$,

- increased strain hardening ability,

- density lower than $8.35 \mathrm{~g} . \mathrm{cm}^{-3}$.

\author{
Experimental Alloys
}

\section{Alloy Design}

Superalloys such as MERL76, AF115 or N18 show some drawbacks due to their high $\gamma^{\prime}$ volume fraction. In particular, they exhibit high $\gamma^{\prime}$ solvus temperatures $\left(\sim 1190^{\circ} \mathrm{C}\right)$ and very narrow solution heat treatment windows [1]. Moreover, the tendency for quench cracking during cooling consecutive to supersolvus heat treatment increases with the amount of $\gamma^{\prime}$ phase [2]. This precludes the possibility to obtain medium or coarse grained microstructure. Finally, N18 alloy is prone to TCP (topologically close-packed) phase precipitation when held at temperature over $650^{\circ} \mathrm{C}$ for long times $[3,4]$.

In order to meet the Snecma specifications, the $\gamma^{\prime}$ fraction of the new superalloys studied in this work was aimed to be in the $40-50 \%$ range. This drop in $\gamma^{\prime}$ amount in comparison with the value of $55 \%$ in alloy N18 was counterbalanced by both $\gamma$ and $\gamma^{\prime}$ strengthening improvements. The $\gamma$ matrix chemistry was optimized through a careful balance between the $\mathrm{Cr}$, Mo and $\mathrm{W}$ elements. The goals were to: i) increase the solid solution hardening of the $\gamma$ matrix, ii) maintain oxidation and corrosion resistances by means of sufficient $\mathrm{Cr}$ addition, iii) avoid or limit the precipitation of TCP phases and, iv) limit the increase of the alloy density. A special attention was turned to Co content because of its effects on high temperature creep resistance and, above all, on the $\gamma^{\prime}$ solvus temperature which generally decreases when the Co level increases. To strengthen the $\gamma^{\prime}$ phase, the $[\mathrm{Ti}+\mathrm{Nb}+\mathrm{Ta}] / \mathrm{Al}$ ratio (concentrations in at.\%) was increased to about 1 (vs. 0.57 for alloy N18). Here again, excessive addition of $\mathrm{Ti}$ and/or $\mathrm{Nb}$ and/or $\mathrm{Ta}$ can have detrimental effects on the microstructure and the mechanical properties. A too high elemental ratio (for example, Ti/Al) or global $[\mathrm{Ti}+\mathrm{Nb}+\mathrm{Ta}] / \mathrm{Al}$ ratio can lead to the presence of undesirable elongated plates of intermetallic phases $\left(\eta-\mathrm{Ni}_{3} \mathrm{Ti}, \delta-\mathrm{Ni}_{3}(\mathrm{Nb}, \mathrm{Ta}), \ldots\right)$. Although $\mathrm{Nb}$ has a stronger strengthening effect than $\mathrm{Ti}$, excessive $\mathrm{Nb}$ content is likely to be deleterious to crack propagation resistance and ductility [5].

Lastly, no particular study was dedicated to the effects of minor elements. For all the experimental alloys, carbon was kept in the $150-320$ wt. ppm range and boron was in the 150-200 wt. ppm range, hafnium content was about $0.3 \mathrm{wt} . \%$ and zirconium, when added, was in the 600-630 wt. ppm range.

The chemistry of the baseline composition (alloy \#1) was balanced using a program based on the method developed by Watanabe [6] for calculation of the $\gamma^{\prime}$ phase fraction and the 
Table I. Nominal Chemistries of Reference Alloys N18 and René 88 and of Some Experimental Alloys (at.\%)

\begin{tabular}{|c|c|c|c|c|c|c|c|c|c|c|c|c|c|}
\hline Alloy & Ni & Co & Cr & Mo & W & Al & Ti & Ta & Nb & Hf & B & C & $\mathrm{Zr}$ \\
\hline N18 (REP) & Bal. & 14.9 & 12.4 & 3.8 & - & 9.1 & 5.1 & - & - & 0.13 & 0.09 & 0.07 & 0.02 \\
\hline R88 (REP) & Bal. & 12.8 & 17.9 & 2.4 & 1.3 & 4.6 & 4.5 & - & 0.4 & - & 0.09 & 0.19 & 0.03 \\
\hline$\# 1$ & Bal. & 10.0 & 15.0 & 4.0 & - & 5.5 & 5.6 & - & - & 0.10 & 0.08 & 0.07 & 0.04 \\
\hline$\# 4$ & Bal. & 10.0 & 15.0 & 2.5 & 1.5 & 5.5 & 5.6 & - & - & 0.09 & 0.08 & 0.07 & 0.04 \\
\hline$\# 7$ & Bal. & 10.0 & 15.0 & 4.0 & - & 5.6 & 4.1 & 1.5 & - & 0.10 & 0.08 & 0.07 & 0.04 \\
\hline$\# 10$ & Bal. & 10.0 & 15.0 & 4.0 & - & 5.6 & 4.1 & - & 1.5 & 0.10 & 0.08 & 0.07 & 0.04 \\
\hline$\# 11$ & Bal. & - & 14.9 & 4.8 & - & 5.5 & 5.5 & - & - & 0.10 & 0.08 & 0.07 & 0.04 \\
\hline$\# 12$ & Bal. & 15.0 & 14.0 & 2.5 & 1.5 & 6.0 & 5.0 & - & 1.0 & 0.10 & 0.09 & 0.12 & - \\
\hline$\# 13$ & Bal. & 15.0 & 14.0 & 3.0 & 0.8 & 4.5 & 6.5 & - & 1.0 & 0.10 & 0.09 & 0.12 & - \\
\hline$\# 14$ & Bal. & 15.0 & 13.5 & 2.2 & 1.3 & 6.3 & 5.7 & - & 0.5 & 0.10 & 0.10 & 0.12 & - \\
\hline$\# 18$ & Bal. & 8.9 & 13.2 & 3.2 & 0.5 & 6.4 & 5.7 & 0.5 & 0.5 & 0.10 & 0.09 & 0.14 & 0.04 \\
\hline$\# 22$ & Bal. & 12.0 & 14.6 & 2.9 & 1.0 & 5.5 & 4.6 & - & 1.0 & 0.10 & 0.08 & 0.10 & 0.04 \\
\hline
\end{tabular}

respective $\gamma$ and $\gamma^{\prime}$ compositions from the alloy chemistry. The densities of the experimental alloys were estimated using the formula developed by Hull [7]. The New PHACOMP method was used to calculate the $\mathrm{Md} \gamma$ parameter and to avoid TCP phase precipitation [8]. The design criteria of the baseline alloy were the following: i) $\gamma^{\prime}$ fraction $=40$ at. $\%$, ii) $\mathrm{Md} \gamma=0.915$, iii) $\mathrm{Cr}$ content fixed at 23 at. $\%$ in the $\gamma$ matrix and, iv) $[\mathrm{Ti}+\mathrm{Nb}+\mathrm{Ta}] / \mathrm{Al}=1$ (concentrations in at.\%).

The computed composition of the baseline alloy (alloy \#1) is given in Table I. Three series of three alloys were also designed with partial substitutions of $\mathrm{W}$ for $\mathrm{Mo}$, Ta for $\mathrm{Ti}$ or $\mathrm{Nb}$ for $\mathrm{Ti}$. The compositions of the alloys with the highest levels of substitution are listed in Table I. Other alloy compositions were adjusted by mixing substitutions or to test some concepts (for example, no Co addition, $\gamma$ ' fraction or $[\mathrm{Ti}+\mathrm{Nb}+\mathrm{Ta}] / \mathrm{Al}$ ratio increases).

\section{$\underline{\text { Processing }}$}

22 experimental alloys and the two reference alloys N18 and René 88 (R88) [2] were processed by laboratory powder metallurgy route. Electrodes of each grade were machined from vacuum induction melted ingots of about $3.2 \mathrm{~kg}$. Prealloyed powders were produced by the rotating electrode process (REP).

The $\gamma^{\prime}$ solvus (Ts) and incipient melting (Tim) temperatures were determined for each alloy by differential thermal analysis (DTA) on REP powders. Analysis of a homemade database allowed correlating these $\gamma$ ' solvus temperatures with those determined by optical microscopy (OM) assessments of consolidated and heat treated (HT) samples (Figure 1).

Powders with size in the $63-200 \mu \mathrm{m}$ range were loaded into steel cans which were then vacuum sealed. Full consolidation was obtained by extrusion in subsolvus conditions $\left(\mathrm{Ts}-25^{\circ} \mathrm{C}\right)$ and with an extrusion ratio of $8: 1$. For a few alloys, hot isostatic pressing and homogenisation heat treatment were necessary before extrusion to prevent some incipient melting events. This problem is sometimes encountered when using REP powders which can be chemically less homogeneous than gas atomised powders (because of the local melting of the consumable electrode in comparison with the total ingot melting previously to gas atomisation).

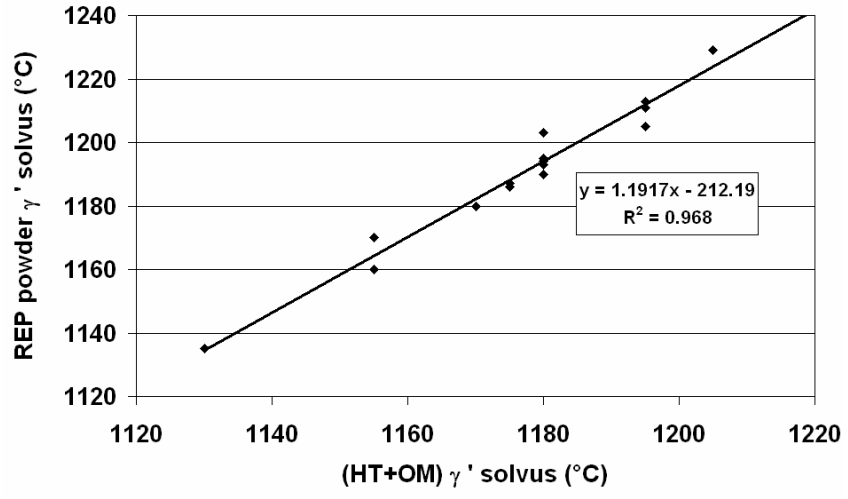

Figure 1. Relationship between DTA REP powder $\gamma^{\prime}$ solvus and $\gamma$ ' solvus determined by metallographic assessments $(\mathrm{HT}+\mathrm{OM})$.

All the alloys were then heat-treated for four hours below the $\gamma^{\prime}$ solvus temperature $\left(\mathrm{Ts}-25^{\circ} \mathrm{C}\right)$. The average cooling rate was controlled to be about $150^{\circ} \mathrm{C} / \mathrm{min}$. Finally, a single step ageing treatment was conducted at $750^{\circ} \mathrm{C}$ during 24 hours and followed by an air cooling.

\section{Microstructures and Metallurgical Data}

Microstructures. Microstructural assessments of the fully heattreated extruded bars of the experimental alloys revealed the following features (Figure 2):

- grain size within the range 5-20 $\mu \mathrm{m}$ (8-12 ASTM). Some alloys show areas with larger grain size (up to $50 \mu \mathrm{m}$ ). As previously mentioned, localized chemical heterogeneities due to the use of REP powders can explain this phenomenon,

- undissolved primary $\gamma^{\prime}$ particles which pin the grain boundaries and limit the grain growth,

- secondary $\gamma^{\prime}$ precipitates with a more or less cuboidal shape depending on the alloy and with a size in the 100-250 nm range,

- fine tertiary $\gamma^{\prime}$ precipitates in the largest $\gamma$ channels or near the grain boundaries (hardly visible on scanning electron microscopy (SEM) images). 
Table II. Metallurgical Data of Reference Alloys N18 and René 88 and of Some Experimental Alloys

\begin{tabular}{|c|c|c|c|c|c|c|c|c|c|}
\hline Alloy & $\begin{array}{l}\text { Calculated } \\
\gamma^{\prime} \text { fraction } \\
\text { (at.\%) }\end{array}$ & $\begin{array}{l}\text { Measured } \\
\gamma^{\prime} \text { solvus } \\
\text { Ts }\left({ }^{\circ} \mathrm{C}\right)\end{array}$ & $\begin{array}{l}\text { Solution } \\
\text { "window" } \\
\text { Tim-Ts } \\
\left({ }^{\circ} \mathrm{C}\right)\end{array}$ & $\begin{array}{l}\text { Measured } \\
\text { density } \\
\left(\mathrm{g} / \mathrm{cm}^{3}\right)\end{array}$ & $\mathrm{Md} \gamma$ & $\begin{array}{l}\text { TCP } \\
\text { phase } \\
\text { occurr } \\
\text { ence }\end{array}$ & $\begin{array}{c}\mathrm{Ti} / \mathrm{Al} \\
\text { (at.\%/at } \\
. \%)\end{array}$ & $\begin{array}{l}{[\mathrm{Nb}+\mathrm{Ta}] / \mathrm{Al}} \\
(\text { at.\%/at.\%) }\end{array}$ & $\begin{array}{c}\text { Platelet shape } \\
\text { particle } \\
\text { location }\end{array}$ \\
\hline N18 (REP) & 56 & 1194 & 33 & 7.97 & 0.942 & XXX & 0.57 & 0 & 0 \\
\hline R88 (REP) & 37 & 1130 & 100 & 8.26 & 0.916 & $\varepsilon$ & 0.97 & 0.1 & 0 \\
\hline$\# 1$ & 42 & 1177 & 73 & 8.09 & 0.915 & $\mathrm{XX}$ & 1.01 & 0 & 0 \\
\hline$\# 4$ & 43 & 1179 & 57 & 8.29 & 0.918 & $\mathrm{X}$ & 1.02 & 0 & 0 \\
\hline$\# 7$ & 44 & 1173 & 63 & 8.37 & 0.917 & $\mathrm{XX}$ & 0.76 & 0.27 & volume \\
\hline$\# 10$ & 44 & 1166 & 79 & 8.18 & 0.916 & $\mathrm{XX}$ & 0.74 & 0.27 & local \\
\hline$\# 11$ & 42 & 1192 & 40 & 8.11 & 0.922 & $\mathrm{XX}$ & 1.02 & 0 & 0 \\
\hline$\# 12$ & 48 & 1175 & 64 & 8.31 & 0.920 & $\mathrm{XX}$ & 0.84 & 0.16 & 0 \\
\hline$\# 13$ & 48 & 1178 & 46 & 8.23 & 0.918 & $\mathrm{XXX}$ & 1.45 & 0.22 & volume \\
\hline$\# 14$ & 49 & 1172 & 57 & 8.24 & 0.915 & 0 & 0.88 & 0.08 & 0 \\
\hline$\# 18$ & 52 & 1192 & 20 & 8.23 & 0.917 & $\mathrm{XX}$ & 0.92 & 0.15 & 0 \\
\hline$\# 22$ & 43 & 1153 & 75 & $8.30^{*}$ & 0.909 & $\varepsilon$ & 0.90 & 0.17 & Very local \\
\hline
\end{tabular}

* estimated density

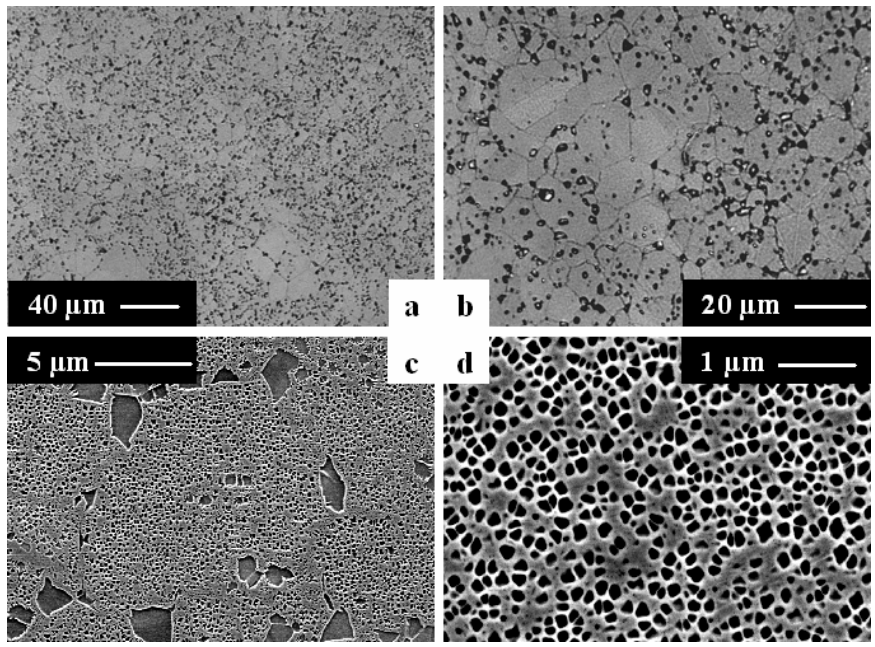

Figure 2. Microstructure of alloy \#1: a) and b) OM; c) and d) SEM.

Platelet shape particles were noticed in a few alloys (Table II). Depending on the alloy, these platelets were located in a few prior powder particles (alloy \#22) or were observed all over the samples (alloys \#7 and \#13) (Figure 3). In alloy \#13, these platelets were identified by electron diffraction to be $\eta$ phase. It is assumed that the localized precipitation of these platelets in a few alloys is once again the result of some chemical heterogeneity of the REP powders.

The proneness of the experimental alloys to TCP phase precipitation was checked after long-term exposure at $750^{\circ} \mathrm{C}$ for 500 hours. Half of the 22 alloys were considered to have acceptable phase stability (Table II): three alloys with no TCP phase (0), three alloys with negligible amount of TCP phase $(\varepsilon)$ and five alloys with low amount of TCP phase particles (X). The other 11 alloys exhibited amounts of TCP phase particles considered too high for the application (XX or XXX) (Figure 4). However, it can be pointed out that these alloys (except alloy \#13) were less prone to the precipitation of TCP phases than the N18 alloy.

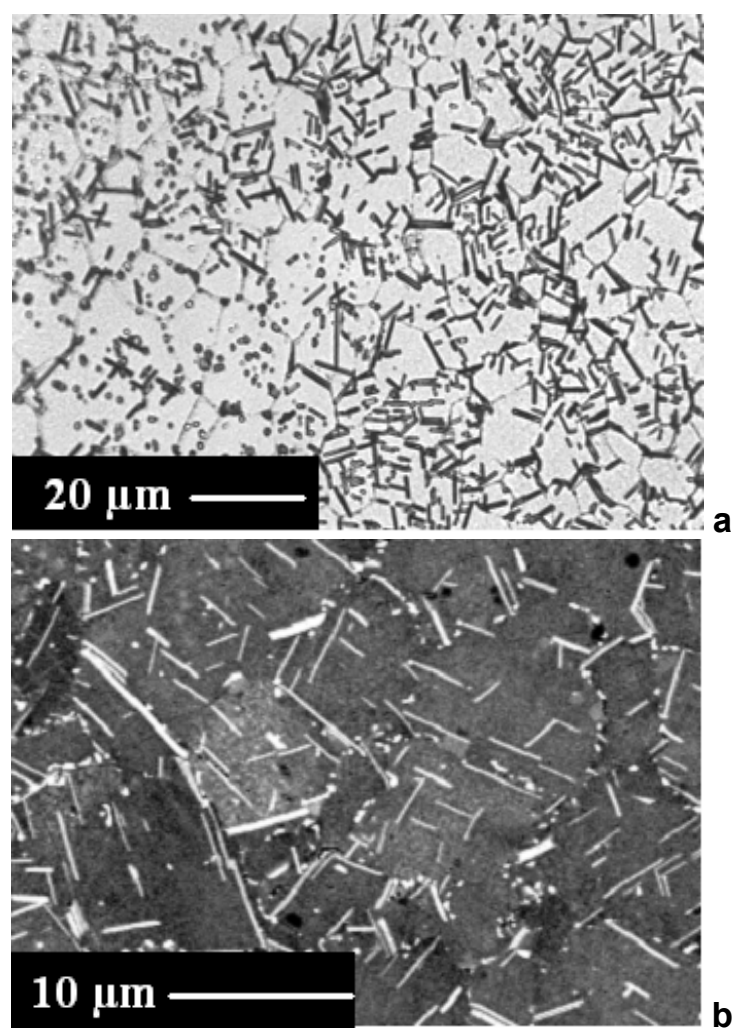

Figure 3. Platelet shape precipitates in fully heat-treated alloy \#7: a) OM and b) SEM.

Metallurgical Data. Computed or measured metallurgical data as well as microstructural examination results are gathered in Table II. The heat treatment windows were determined using the values of Tim and Ts measured by DTA on REP powders, whereas the $\gamma$ ' solvus temperatures in Table II were deduced from the relation of Figure 1. $\gamma^{\prime}$ fraction and $\mathrm{Md} \gamma$ were computed using a homemade program. Densities were measured using the Archimedes' method in xylene. 

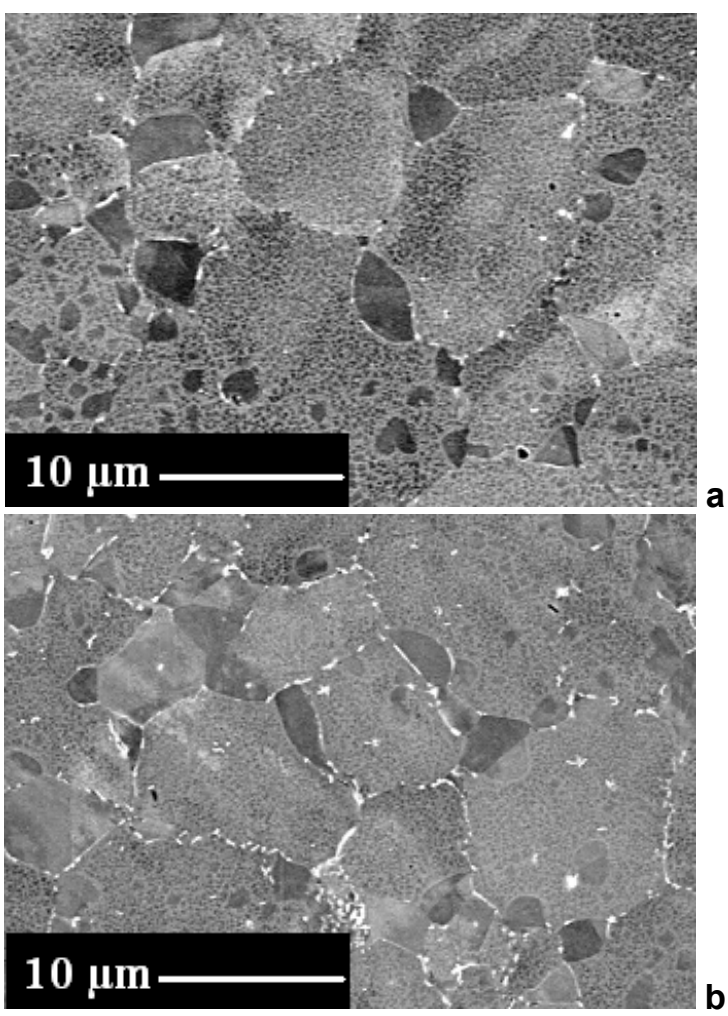

Figure 4. Examples of TCP phase precipitation after exposure for 500 hours at $750^{\circ} \mathrm{C}$ : a) alloy $\# 4$ with acceptable TCP phase precipitation and b) alloy \#18 with quasi-continuous intergranular TCP phase precipitation (SEM, TCP phase precipitates appear as white particles at the grain boundaries).

The synthesis of the microstructural assessments of the 24 alloys after long-term ageing allows to conclude that there is no or negligible $(0$ or $\varepsilon)$ TCP phase precipitation when $\mathrm{Md} \gamma$ is less than or equal to 0.910 and that amount of TCP phase precipitates is too high (XX or XXX) when Md $\gamma$ is greater than 0.918. When Md $\gamma$ is between these two values, the alloy can exhibit no (alloy \#14) or excessive TCP phase precipitation (alloys \#7, 10 and 18).
A too high $\mathrm{Ti} / \mathrm{Al}$ ratio leads to bulk precipitation of $\eta$ phase (alloy \#13, $\mathrm{Ti} / \mathrm{Al}=1.45$ ) [9]. But even with a moderate $\mathrm{Ti} / \mathrm{Al}$ ratio (close to 1), platelet phase precipitation can occur very locally when $[\mathrm{Nb}+\mathrm{Ta}] / \mathrm{Al}$ ratio is higher than 0.17 (alloy \#22) or in all the volume of the material when this ratio is close to 0.27 (alloy \#7).

\section{Mechanical Properties}

In this first stage of the study, only tensile and creep tests were performed on each alloy for ranking and comparison with the mechanical resistance specifications (Table III). Tensile properties of each of the 24 alloys were determined at room temperature (RT), $650^{\circ} \mathrm{C}$ and for some alloys at $700^{\circ} \mathrm{C}$. Times for $0.2 \%$ tensile creep strain were determined at $700^{\circ} \mathrm{C}$ and 550 or $650 \mathrm{MPa}$ by performing constant load tests in air.

For most of the 22 experimental alloys, the mechanical properties are higher than those of N18 or René 88 alloys. Alloy \#1 (with low $\gamma$ ' fraction and no $\mathrm{Nb}$, Ta or $\mathrm{W}$ ) has mechanical properties relatively close to those of $\mathrm{N} 18$ alloy. When substituting Ni for Co in alloy \#1, it gives alloy \#11 which exhibits slightly lower tensile properties as compared to N18 alloy but, above all, a much lower creep strength. These trends where previously reported in other disk superalloys $[10,11]$ as well as the $\gamma^{\prime}$ solvus temperature increase when cobalt is partially or totally removed from superalloys.

\section{$\underline{\text { Selection of Two Alloys }}$}

Two experimental alloys were selected on the basis of their metallurgical data, microstructural examinations and mechanical properties, to be processed through an industrial route and to be more thoroughly evaluated.

N18 and René 88 were chosen as reference alloys. To avoid comparison between materials produced by different metallurgical routes, N18 and René 88 were processed using the same technologies (REP and extrusion) as for the experimental alloys.

Screening of the experimental alloys was performed as follows:

- four alloys (\#17, 18, 19 and 20) were dismissed because of their

Table III. Static Mechanical Properties of Reference Alloys N18 and René 88 and of Some Experimental Alloys

\begin{tabular}{|c|c|c|c|c|c|c|c|c|}
\cline { 2 - 9 } \multicolumn{1}{c|}{} & \multicolumn{9}{c|}{ Tensile properties } & \multicolumn{3}{c|}{ Creep properties } \\
\cline { 2 - 9 } \multicolumn{1}{c|}{} & \multicolumn{2}{c|}{ RT } & \multicolumn{2}{c|}{$650^{\circ} \mathrm{C}$} & \multicolumn{2}{c|}{$700^{\circ} \mathrm{C}$} & $700^{\circ} \mathrm{C} / 650 \mathrm{MPa}$ & $700^{\circ} \mathrm{C} / 550 \mathrm{MPa}$ \\
\hline \multirow{2}{*}{ Alloy } & $\begin{array}{c}0.2 \% \text { YS } \\
(\mathrm{MPa})\end{array}$ & $\begin{array}{c}\text { UTS } \\
(\mathrm{MPa})\end{array}$ & $\begin{array}{c}0.2 \% \text { YS } \\
(\mathrm{MPa})\end{array}$ & $\begin{array}{c}\text { UTS } \\
(\mathrm{MPa})\end{array}$ & $\begin{array}{c}0.2 \% \mathrm{YS} \\
\mathrm{MPa})\end{array}$ & $\begin{array}{c}\mathrm{UTS} \\
(\mathrm{MPa})\end{array}$ & $\mathrm{t}_{0.2 \%}(\mathrm{~h})$ & $\mathrm{t}_{0.2 \%}(\mathrm{~h})$ \\
\hline N18 (REP) & 1130 & 1633 & 1076 & 1474 & - & - & - & 340 \\
\hline R88 (REP) & 1211 & 1618 & 1091 & 1445 & 1080 & 1224 & - & 585 \\
\hline$\# 1$ & 1151 & 1626 & 1041 & 1487 & - & - & - & 230 \\
\hline$\# 4$ & 1193 & 1612 & 1098 & 1546 & - & - & - & 410 \\
\hline$\# 7$ & 1233 & 1617 & 1132 & 1590 & - & - & - & 155 \\
\hline$\# 10$ & 1197 & 1650 & 1092 & 1565 & - & - & - & 395 \\
\hline$\# 11$ & 1110 & 1589 & 1006 & 1464 & - & - & - & 36 \\
\hline$\# 12$ & 1270 & 1715 & 1162 & 1635 & 1119 & 1373 & - & 2310 \\
\hline$\# 13$ & 1228 & 1544 & 1121 & 1558 & 973 & 973 & - & 555 \\
\hline$\# 14$ & 1198 & 1643 & 1132 & 1590 & 1103 & 1351 & $>1600$ & - \\
\hline$\# 18$ & 1191 & 1642 & 1114 & 1529 & 1105 & 1410 & 169 & - \\
\hline$\# 22$ & 1220 & 1649 & 1102 & 1589 & 1097 & 1448 & 462 & - \\
\hline
\end{tabular}


too narrow solution heat treatment window $\left(17-20^{\circ} \mathrm{C}\right.$, narrower than the one of N18). Their high $\gamma^{\prime}$ solvus temperatures are due to their large $\gamma$ ' fraction (48-52\%) and their incipient melting temperatures are low because of their large boron content [12]. A wider solution window is required for a better suitability for supersolvus solutioning,

- alloy \#7 was rejected because of its excessive density,

- eleven alloys were eliminated because of their too high amount of TCP phase precipitates after ageing at $750^{\circ} \mathrm{C}$ for 500 hours (alloys \#1, 5-13, 18 and 20),

- two alloys were discarded because of platelet phase precipitation (alloys \#7 and 13). This generalized precipitation has detrimental effect on the ductility of these alloys especially at high temperature,

- three more alloys (alloys \#2, 3 and 4) were pushed aside as their tensile and creep resistances are only moderate and TCP phase proneness is not negligible.

Eventually, among the five remaining alloys (alloys \#14, 15, 16, 20 and 22), the selection of the two most promising alloys was achieved as follows:

- alloy \#14 (SMO48 alloy) was selected because of its high tensile and creep resistances together with its good phase stability,

- alloy \#22 (SMO43 alloy) was selected because of its high tensile resistance. Its creep resistance is quite moderate as compared with alloy \#14. However, this alloy exhibits lower $\gamma$ ' fraction and lower $\gamma^{\prime}$ solvus temperature than those of alloy \#14.

A patent on the selected alloy compositions was filed [13, 14].

\section{Evaluation of Selected Alloys}

\section{$\underline{\text { Alloys Processing }}$}

Vacuum induction ingots of SMO43 and SMO48 were provided by Aubert \& Duval. Powders of the two alloys were produced using an argon atomisation industrial facility (Aubert \& Duval). The powders were subsequently processed according to the industrial route implemented for N18 PM alloy: sieving $(<53 \mu \mathrm{m}$ $(-270$ mesh) $)$, container filling and hot isostatic pressing $\left(1150^{\circ} \mathrm{C}\right)$. Two bars (70 $\mathrm{mm}$ diameter / $700 \mathrm{~mm}$ length) were obtained using an extrusion press at Snecma, with conditions determined from Snecma experience on both Astroloy and N18, in particular as regards the extrusion temperature which is quite below the $\gamma^{\prime}$ solvus temperature (Figure 5).

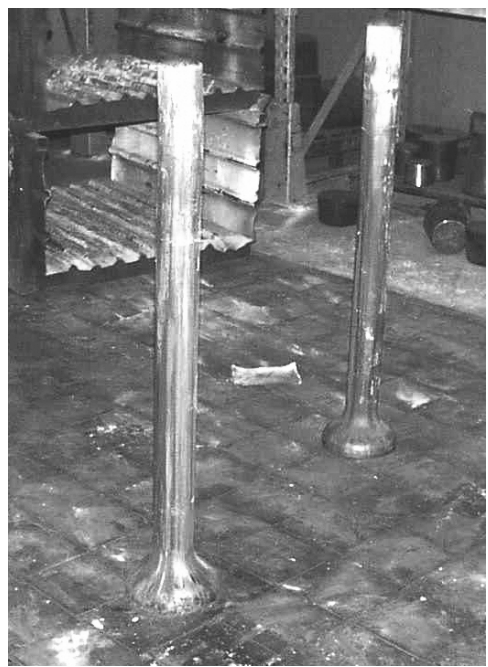

Figure 5. Extruded bars of SMO43 and SMO48 alloys.

Mults cut from extruded billets were isothermally forged at Snecma to obtain four pancakes (about $200 \mathrm{~mm}$ diameter) of each alloy (Figure 6). Finally, a supersolvus heat treatment was applied on the pancakes of both alloys in order to get a medium grain size around $50 \mu \mathrm{m}$, followed by a single step ageing treatment at $750^{\circ} \mathrm{C}$ for 24 hours with air cooling.

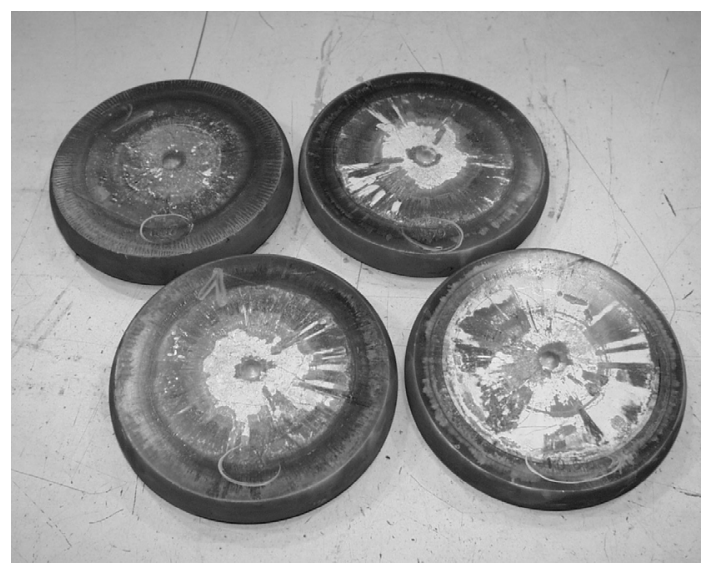

Figure 6. Isothermally forged pancakes of SMO43 and SMO48 alloys.

\section{Metallurgical Data and Microstructures}

Chemical Compositions. The results of the chemical analyses of SMO43 and SMO48 alloys reported in Table IV are in agreement with the delivered specifications in the limits of the patent.

Table IV. Chemical Compositions of SMO43 and SMO48 Alloys (wt.\%)

\begin{tabular}{|c|c|c|c|c|c|c|c|c|c|c|c|c|}
\hline Alloy & Ni & Co & Cr & Mo & W & Al & Ti & Nb & Hf & B & C & $\mathrm{Zr}$ \\
\hline SMO48 & Bal. & 14.9 & 12.3 & 3.6 & 4.0 & 3.2 & 4.4 & 0.8 & 0.30 & 0.01 & 0.030 & - \\
\hline SMO43 & Bal. & 12.2 & 13.3 & 4.6 & 3.0 & 2.9 & 3.6 & 1.5 & 0.25 & 0.01 & 0.015 & 0.05 \\
\hline
\end{tabular}


Physical Properties. The amount of $\gamma^{\prime}$ phase at RT was calculated to be respectively close to 43 at. $\%$ and 48 at. $\%$ in SMO43 and SMO48. For the sake of comparison, the fraction of $\gamma^{\prime}$ phase is about 55 at.\% in N18. Prior to extrusion, the $\gamma^{\prime}$ solvus temperature was determined by micrographic examination and DTA on HIP'ed samples. For each alloy, both techniques led to the same value: $1145^{\circ} \mathrm{C}$ for $\mathrm{SMO} 43$ and $1175^{\circ} \mathrm{C}$ for SMO48. As expected, these two values are below the N18 $\gamma^{\prime}$ solvus temperature $\left(1195^{\circ} \mathrm{C}\right)$, but slightly above the R88 $\gamma^{\prime}$ solvus temperature $\left(1135^{\circ} \mathrm{C}\right)$ for SMO43. The alloy densities were measured to be

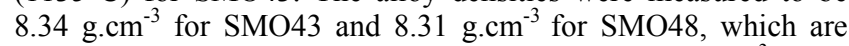
comparable to the density of René $88\left(8.33 \mathrm{~g} . \mathrm{cm}^{-3}\right)$ and significantly higher than that of N18 $\left(8.00 \mathrm{~g} . \mathrm{cm}^{-3}\right)$.

Microstructures. Samples were taken from the fully heat-treated pancakes. The SEM investigations revealed the following features (Figure 7 and Figure 8):

- complete $\gamma^{\prime}$ solutioning as expected (no primary $\gamma^{\prime}$ at the grain boundaries),

- rather homogeneous grain sizes in the 40-60 $\mu \mathrm{m}$ range (ASTM 5-6),

- secondary $\gamma^{\prime}$ precipitates exhibiting two times larger sizes in $\mathrm{SMO} 48$ as compared to $\mathrm{SMO} 43(0.7$ to $1.0 \mu \mathrm{m}$ versus 0.3 to $0.6 \mu \mathrm{m})$,

- homogeneous distribution of fine $(<0.1 \mu \mathrm{m})$ tertiary $\gamma^{\prime}$ precipitates in both alloys,

- small porosities $(<10 \mu \mathrm{m})$ and some Hf oxide rafts $(<50 \mu \mathrm{m})$ as already observed in N18.

Microstructural stability assessments were carried out on these grades during the alloy development phase and have enabled to check the phase stability of both alloys during long-term ageing: no needle like phase precipitation contrary to what observed in N18, but early signs of intergranular precipitation can however be noticed.

\section{$\underline{\text { Mechanical Properties }}$}

Tensile Strength. SMO43 and SMO48 alloys with a medium grain size exhibit quite similar $0.2 \%$ yield (YS) and ultimate (UTS) tensile strengths, also comparable to that of the N18 reference alloy with a fine grained (FG) microstructure (Figure 9). It can thus be expected that the tensile resistance of SMO alloys could be increased if required. FG microstructures obtained through subsolvus heat treatments should indeed enable to get a significant tensile strength increase as usually observed in PM superalloys. Up to $400^{\circ} \mathrm{C}$, the $\mathrm{SMO}$ alloy ductilities are low as compared to N18 but remain quite acceptable (Figure 10).
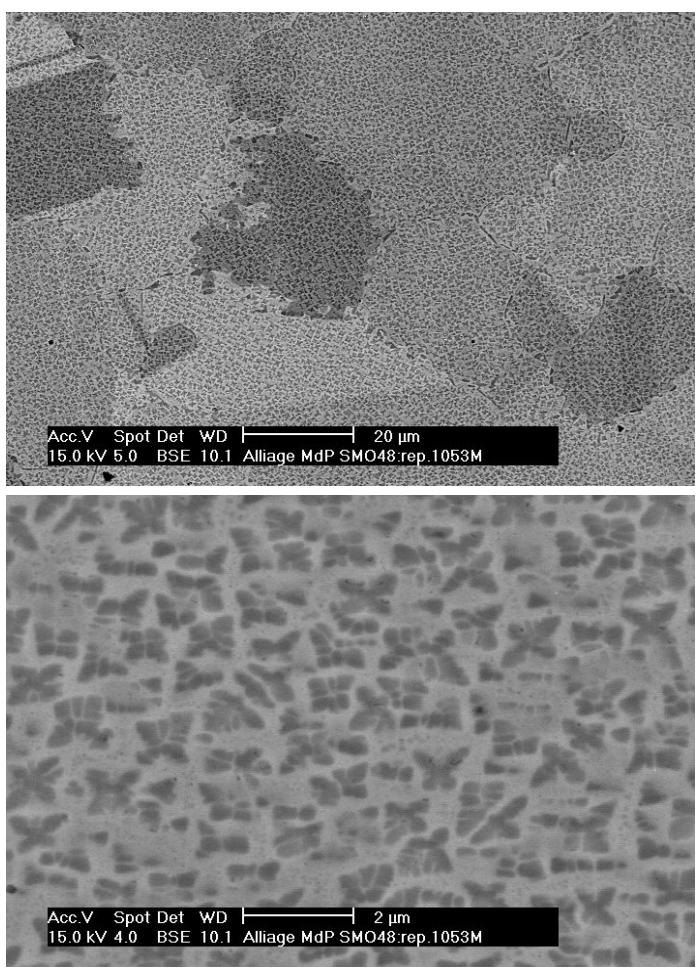

Figure 7. SMO48 microstructure (SEM).
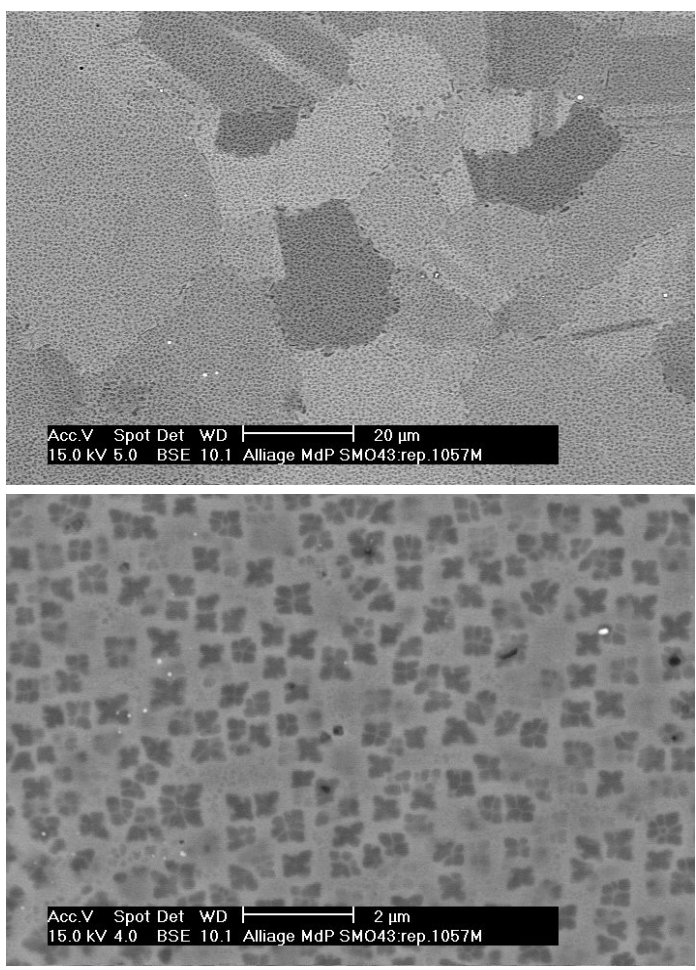

Figure 8. SMO43 microstructure (SEM). 


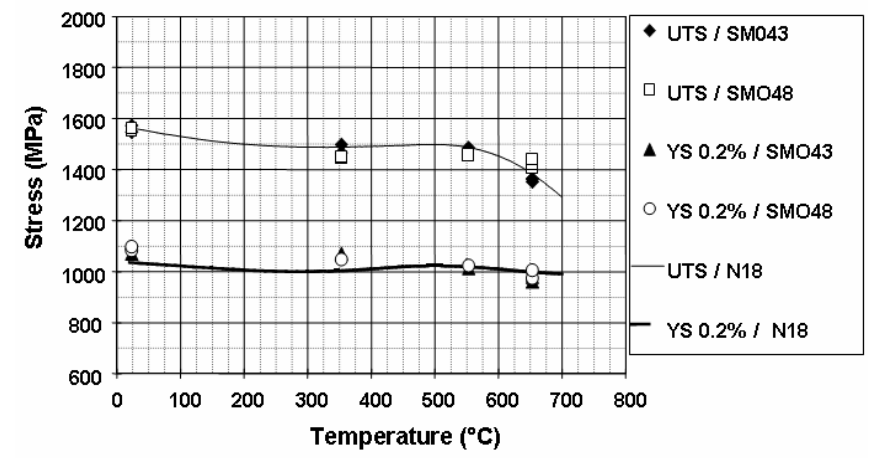

Figure 9: Tensile strength of SMO alloys with a medium grain size and of the N18 reference alloy with a fine grain size.

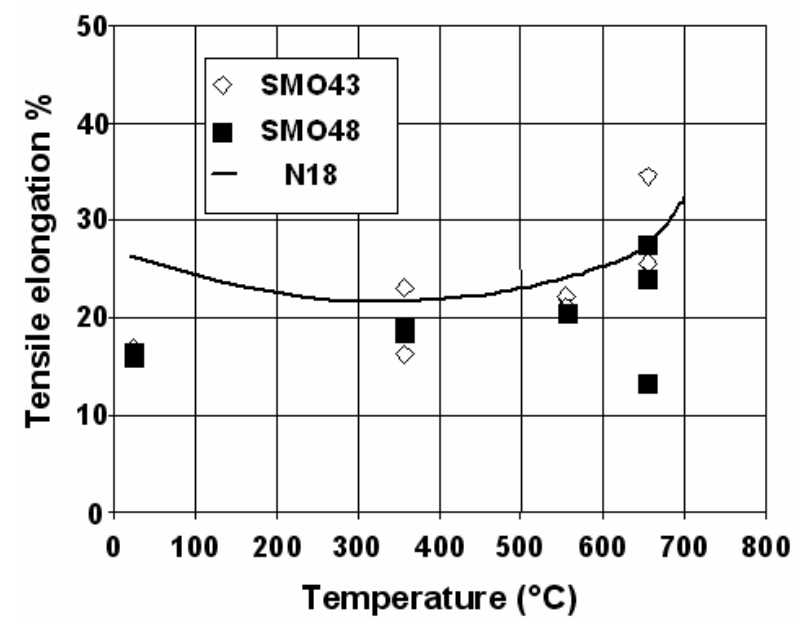

Figure 10: Tensile elongation of SMO alloys with a medium grain size and of the N18 reference alloy with a fine grain size.

Creep Behaviour. Tensile creep tests were performed in air at 650 and $750^{\circ} \mathrm{C}$ and the times for $0.2 \%$ elongation were recorded (Figure 11). Both SMO alloys exhibit a creep strength at $650^{\circ} \mathrm{C}$ significantly higher than that of FG N18, with a ten to fifty times creep rupture life improvement corresponding to a $100^{\circ} \mathrm{C}$ increase of the temperature capability. This dramatic improvement in creep resistance is consistent with tailored chemistries for high temperature resistance ( $\gamma$ matrix hardening) associated with a medium grained microstructure fitted for minimizing creep elongation.

Low Cycle Fatigue Behaviour. Strain controlled low cycle fatigue (LCF) tests $(\mathrm{R}=0, \mathrm{f}=0.5 \mathrm{~Hz})$ were performed on smooth cylindrical specimens at 450,550 and $650^{\circ} \mathrm{C}$. In a general manner, the LCF strength of SMO43 is always slightly superior to that of SMO48 (Figure 12). At $650^{\circ} \mathrm{C}, \mathrm{SMO} 43$ is superior to $\mathrm{N} 18$ (average values) at high loading levels and both alloys exhibit quite close LCF strengths at low strain amplitude. This advantage for SMO43 is not observed at lower temperatures. However, it should be emphasized that the microstructures considered in this first study are probably not optimised for LCF resistance. Moreover, as usual in LCF, a definitive conclusion cannot be drawn from a limited number of experimental results.

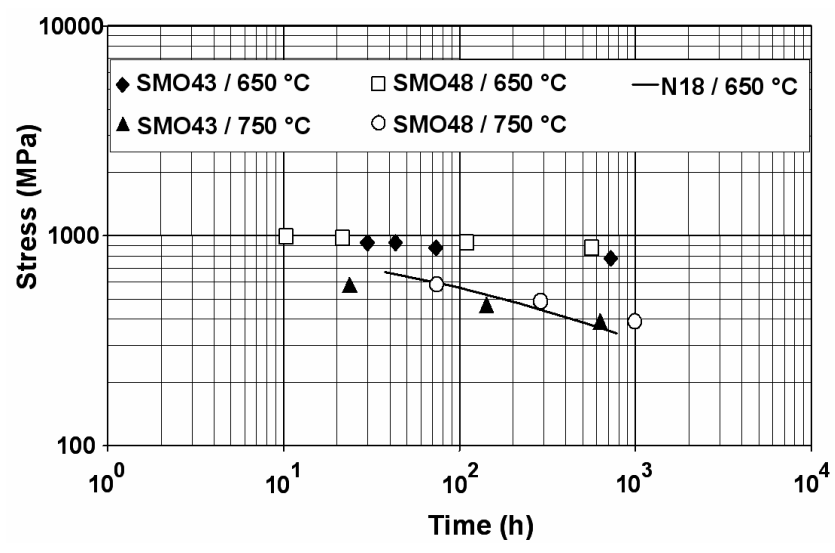

Figure 11: Creep strength at $650^{\circ} \mathrm{C}$ and $750^{\circ} \mathrm{C}$ of SMO alloys compared to that of N18: times for $0.2 \%$ elongation.

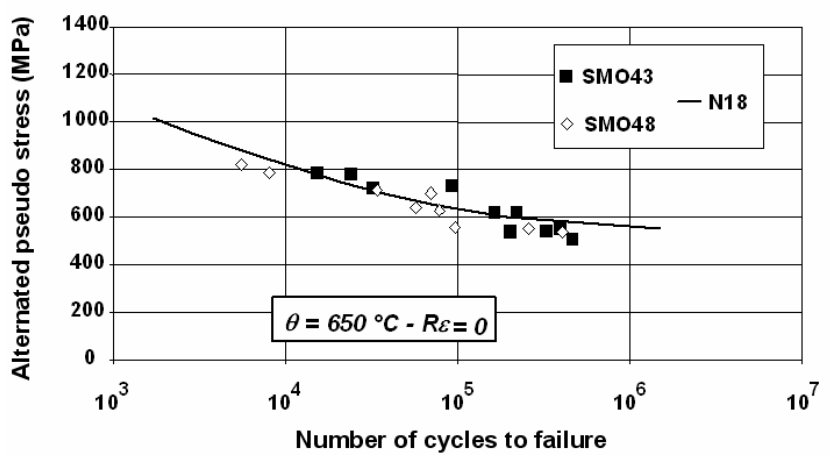

Figure 12: LCF curves of SMO alloys compared to average values of N18.

SEM assessments of the fracture surfaces of the SMO specimens revealed that crack initiation sites are not systematically associated with defects from where cracks usually initiate in PM alloys, such as inclusion or porosity, while it is the case for FG N18. Numerous crystallographic initiation sites with cleavage facets are frequently observed (Figure 13a and 13c) but crack initiations at inclusion are also noticed (Figure 13b and 13d). The percentages of crystallographic crack initiation events on both grades as a function of temperature are presented in Table V.

It should be noticed that only a limited number of LCF tests (about 20 per alloy) were carried out and taken into account in this analysis but the trend to reduced crack initiation at inclusions is clearly evidenced, in particular in SMO43. This can be explained by the larger grain size in SMO alloys as compared to N18, which results in a lower sensitivity to material defects. Moreover, the decrease with increasing temperature of the frequency of the crystallographic crack initiation events is in agreement with previous results published on René 88 [2, 15, 16, 17]. 


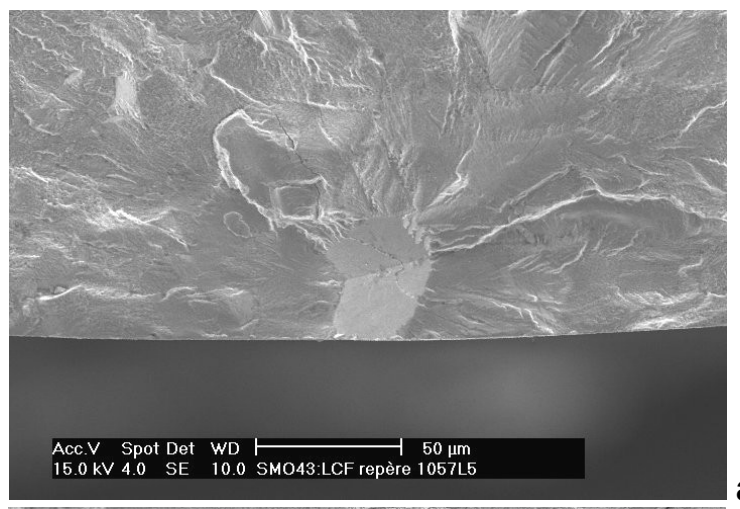

a
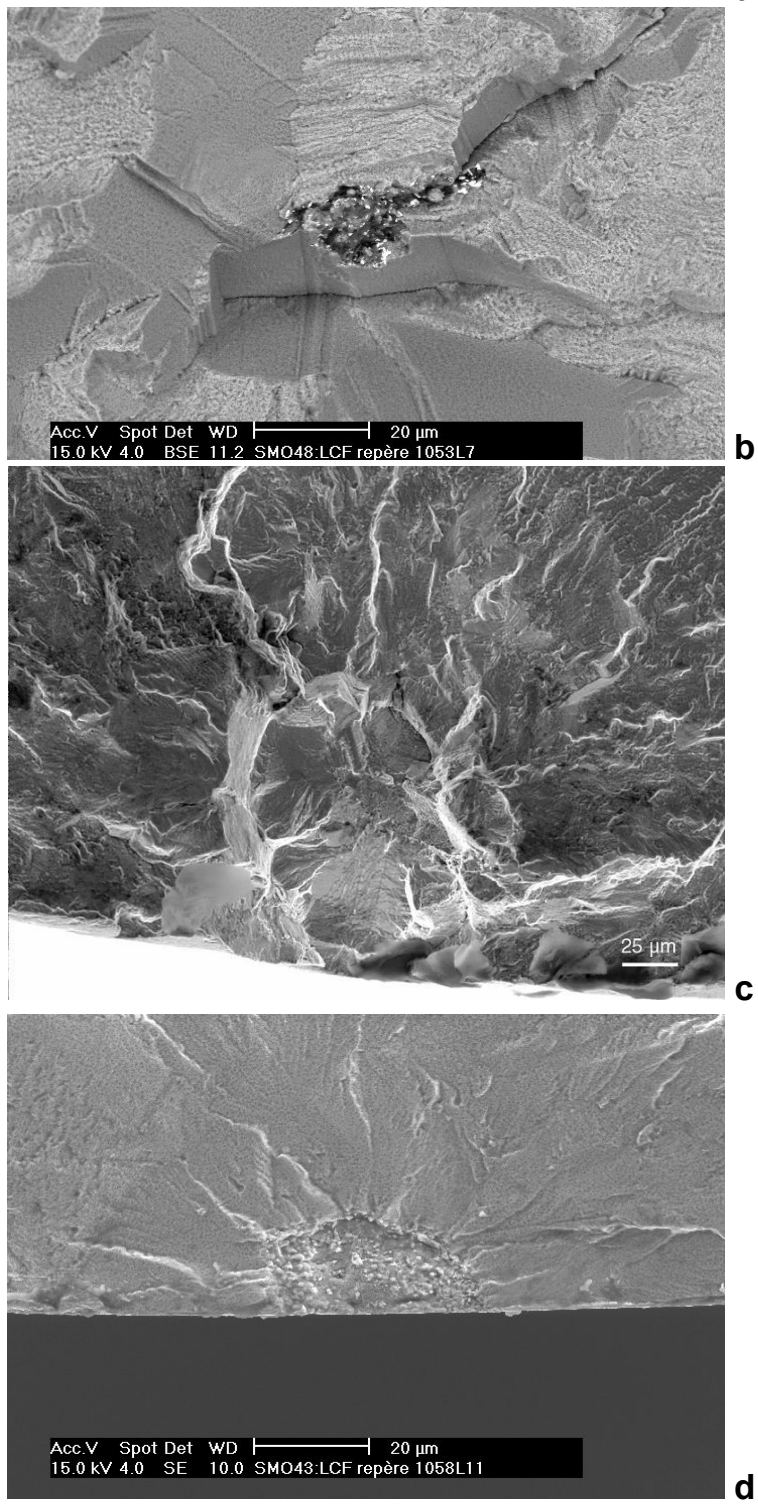

Figure 13: LCF crack initiation sites: a) crystallographic crack initiation in $\mathrm{SMO} 43$ at $450^{\circ} \mathrm{C}$; b) crack initiation at an inclusion in $\mathrm{SMO} 48$ at $550^{\circ} \mathrm{C}$; c) crystallographic crack initiation in $\mathrm{SMO} 43$ at $650^{\circ} \mathrm{C}$; d) crack initiation at an inclusion in SMO43 at $650^{\circ} \mathrm{C}$.
Table V. Percentage of Crystallographic Crack Initiation Events during LCF Tests

\begin{tabular}{|c|c|c|c|}
\cline { 2 - 4 } \multicolumn{1}{c|}{} & \multicolumn{3}{c|}{ Temperature of LCF tests } \\
\cline { 2 - 4 } \multicolumn{1}{c|}{} & $450^{\circ} \mathrm{C}$ & $550^{\circ} \mathrm{C}$ & $650^{\circ} \mathrm{C}$ \\
\hline SMO43 alloy & 100 & 75 & 25 \\
\hline SMO48 alloy & 60 & 57 & 0 \\
\hline
\end{tabular}

Fatigue Crack Propagation Behaviour. Fatigue crack growth (FCG) tests were performed on single-edge-notched (SEN) specimens at $550^{\circ} \mathrm{C}$ (sine waveform with $\mathrm{f}=0.5 \mathrm{~Hz}$ and a load ratio $\mathrm{R}=0.05$ ) and at $650^{\circ} \mathrm{C}$ (sine waveform with $\mathrm{f}=0.5 \mathrm{~Hz}$ and trapezoidal waveform with 10s-300s-10s loading cycle with a load ratio $\mathrm{R}=0$ ) (Figure 14).

Under loading with sine waveform, the crack growth rates of both SMO alloys and $\mathrm{N} 18$ (FG) are very close. At $650^{\circ} \mathrm{C}$ under trapezoidal loading cycle, SMO48 and N18 (FG) exhibit similar fatigue crack growth rates. This indicates a quite good crack propagation behaviour for SMO48 since N18 exhibits one of the highest crack propagation resistances among PM alloys at $650^{\circ} \mathrm{C}$ in fatigue with hold time. SMO43 shows a similar behaviour with a crack growth rate two times higher. According to results obtained on a series of PM superalloys derived from the KM4 alloy [18], the good crack growth resistance of the three alloys can be, at least partly, associated with their Hf content, namely $0.5 \mathrm{wt} . \%$ in N18, 0.2 to $0.3 \mathrm{wt} . \%$ in SMO alloys.

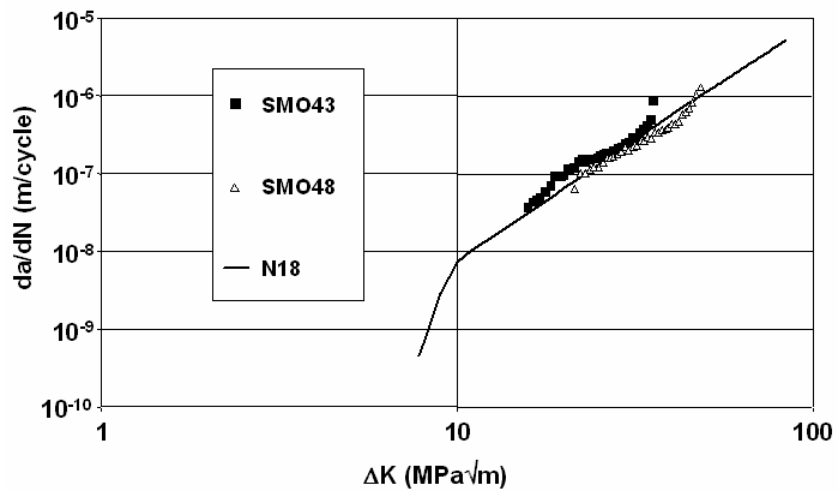

a)

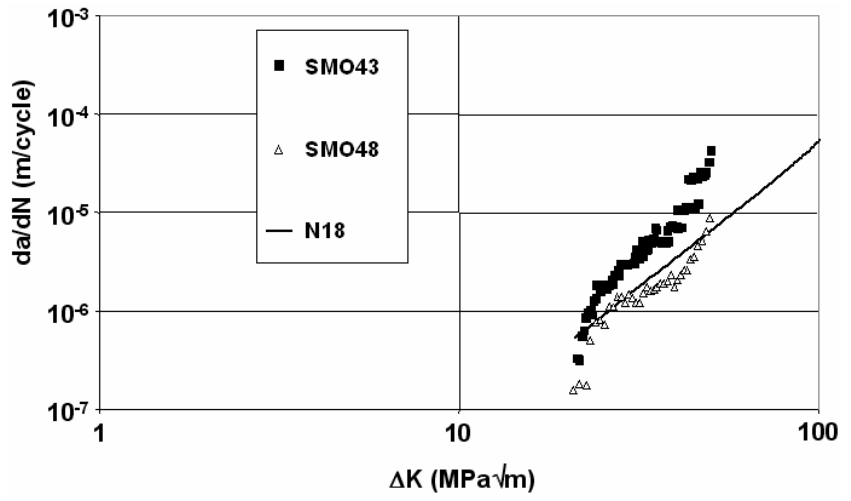

b)

Figure 14: Fatigue crack propagation behaviours of SMO alloys compared to that of $\mathrm{N} 18$ : a) $\mathrm{T}=550^{\circ} \mathrm{C}$, sine waveform with $\mathrm{f}=$ $0.5 \mathrm{~Hz}$; b) $\mathrm{T}=650^{\circ} \mathrm{C}$, trapezoidal waveform with $10 \mathrm{~s}-300 \mathrm{~s}-10 \mathrm{~s}$ loading cycle. 
$\underline{\text { Final Selection }}$

SMO43 and SMO48 alloys exhibit quite similar tensile and fatigue crack growth properties comparable or better than those of N18 alloy. SMO48 has a better creep resistance capability as compared with SMO43 and both alloys are significantly superior to $\mathrm{N} 18$. SMO43 shows the highest LCF strength at $650^{\circ} \mathrm{C}$, no strong difference being noticed at lower temperatures. All these preliminary results sound promising, especially if we consider that the mechanical properties could probably be upgraded since the SMO alloys seem to have a large capability for microstructure adjustments (and consequently mechanical properties) through adequate thermomechanical treatments.

LCF resistance improvement is the basic predominant criterion for a new PM alloy and that is the reason why SMO43 was finally chosen for further evaluation. Moreover, the lower $\gamma$ ' content in SMO43 as compared with SMO48 is another reason for the choice of SMO43. The resulting lower $\gamma$ ' solvus temperature will give a better suitability to this alloy for the whole material manufacturing process, i.e. extrusion, isothermal forging and solution heat treatment. Therefore, complementary studies are in progress in order to optimise the different steps in this process.

\section{Conclusion}

An alloy development program succeeded in identifying a new PM disk superalloy with promising mechanical properties especially high creep and fatigue resistances. Both SMO43 and SMO48 alloys have thus been patented $[13,14]$. The SMO43 alloy (now designated N19) was selected on the basis of:

- a set of high tensile, creep and FCG properties,

- a higher LCF resistance,

- lower $\gamma$ ' fraction and solvus temperature which are key factors for improving thermal and thermomechanical treatment capabilities.

This alloy shows metallurgical capabilities of development with regard to the required properties (monotonic and/or cyclic resistances, use at high temperature). So additional studies are in progress to further improve its mechanical properties through optimised thermal and thermomechanical treatments.

\section{Acknowledgements}

French Defence Agency (DGA) is gratefully acknowledged for financial support.

\section{References}

1. M. Chang, A.K. Koul, C. Cooper, "Damage tolerance of P/M turbine disc materials," Superalloys 1996, ed. R.D. Kissinger et al. (Warrendale, PA, USA: TMS, 1996), 677-685.

$2 . \quad$ D.D. Krueger, R.D. Kissinger, R.G. Menzies, C.S. Wukusick, "Fatigue crack growth resistant nickel-base article and alloy and method for making," US Patent \#4,957,567, 1990.

3. J.-Y. Guédou, J.-C. Lautridou, Y. Honnorat, "N18, PM superalloy for disks: development and applications," Superalloys 1992, ed. S.D. Antolovich et al. (Warrendale, PA, USA: TMS, 1992), 267-276.

4. $\quad$ S.T. Wlodek, M. Kelly, D. Alden, "The structure of N18," Superalloys 1992, ed. S.D. Antolovich et al. (Warrendale, PA, USA: TMS, 1992), 467-476.

5. A. Walder, M. Marty, J.-L. Strudel, E. Bachelet, J.H. Davidson, J.-F. Stohr, "N18, a new high strength, damage tolerant PM superalloy for turbine discs application," (paper presented at ICAS, Jerusalem, Israel, 1988).

6. R. Watanabe, T. Kuno, "Alloy design of nickel-base precipitation hardened superalloys," Transaction ISIJ, 16, (1976), 437-446.

7. F.C. Hull, "Estimating alloy densities," Metal Progress, nov. 1969, 139-140.

8. M. Morinaga, N. Yukawa, H. Adachi, H. Ezaki, "New PHACOMP and its applications to alloy design," Superalloys 1984, ed. M. Gell et al. (Warrendale, PA, USA: The Metallurgical Society of AIME, 1984), 523-532.

9. G.K. Bouse, "Eta $(\eta)$ and platelet phases in investment cast superalloys," Superalloys 1996, ed. R.D. Kissinger et al. (Warrendale, PA, USA: TMS, 1996), 163-172.

10. G.E. Maurer, L.A. Jackman, J.A. Domingue, "Role of cobalt in Waspaloy," Superalloys 1980, ed. J.K. Tien et al. (Metals Park, OH, USA: ASM, 1980), 43-52.

11. R.N. Jarrett, J.K. Tien, "Effects of cobalt on structure, microchemistry and properties of a wrought nickel-base superalloy," Met. Trans. A, 13A (1982), 1021-1032.

12. T.J. Garosshen, T.D. Tillman, G.P. McCarthy, "Effects of $\mathrm{B}, \mathrm{C}$, and $\mathrm{Zr}$ on the structure and properties of $\mathrm{P} / \mathrm{M}$ nickel base superalloy," Met. Trans. A, 18A (1987), 69-77.

13. I. Augustins-Lecallier, P. Caron, J.-Y. Guédou, D. Locq, L. Nazé, European Patent EP 1840232 A1, 29/03/07.

14. I. Augustins-Lecallier, P. Caron, J.-Y. Guédou, D. Locq, L. Nazé, US Patent US 2007/0227630 A1, 30/03/07.

15. E.S. Huron, P.G. Roth, "The influence of inclusions on low cycle fatigue life in a P/M nickel-base disk superalloy," Superalloys 1996, ed. R.D. Kissinger et al. (Warrendale, PA, USA: TMS, 1996), 359-368. 
16. A. Shyam, C.J. Torbet, S.K. Jha, J.M. Larsen, M.J. Caton, C.J. Szczepanski, T.M. Pollock, J.W. Jones, "Development of ultrasonic fatigue for rapid, high temperature fatigue studies in turbine engine materials," Superalloys 2004, ed. K.A. Green et al. (Warrendale, PA, USA: TMS, 2004), 259-268.

17. K.O. Findley, A. Saxena, "Low cycle fatigue in Rene $88 \mathrm{DT}$ at $650^{\circ} \mathrm{C}$ : crack nucleation mechanisms and modeling," Met. Trans. A, 37A (2006), 1469-1475.

18. E.S. Huron, K. R. Bain, D. P. Mourer, J.J. Schirra, P.L. Reynolds, E.E. Montero, "The influence of grain boundary elements on properties and microstructures of $\mathrm{P} / \mathrm{M}$ nickel base superalloys," Superalloys 2004, ed. K.A. Green et al. (Warrendale, PA, USA: TMS, 2004), 73-81. 